\title{
Influence of footwear designed to boost energy return on the kinetics and kinematics of running compared to conventional running shoes
}

\author{
J. Sinclair ${ }^{1 *}$, C. Franks ${ }^{1}$, J.F. Goodwin ${ }^{1}$, R. Naemi ${ }^{2}$ and N. Chockalingam ${ }^{2}$ \\ 1University of Central Lancashire, Fylde road, PR1 2HE Preston, Lancashire, United Kingdom; ${ }^{2}$ Staffordshire University, Leek Road, ST4 2DF \\ Stoke-on-Trent, United Kingdom; jksinclair@uclan.ac.uk
}

Received: 3 July 2014 / Accepted: 23 July 2014

RESEARCH ARTICLE

(c) 2014 Wageningen Academic Publishers

\begin{abstract}
Runners have sought to utilise athletic footwear as one of the mechanisms by which they might attenuate their risk of injury and improve their performance. New commercially available footwear which claims to boost energy return have been designed utilising an expanded thermoplastic polyurethane midsole. These footwear have been shown to improve running economy, but their clinical efficacy has not yet been established. This study aimed to examine the 3-D kinetics and kinematics when running in footwear that claims to promote energy return in relation to conventional running trainers. Fifteen male participants ran at $4.0 \mathrm{~m} / \mathrm{s}( \pm 5 \%)$ in each footwear condition. Lower extremity kinematics were collected in the sagittal, coronal and transverse planes using a 3-D motion analysis system. Simultaneous tibial acceleration and vertical ground reaction force parameters were also obtained. Impact parameters and 3-D kinematics were contrasted using paired samples t-tests. The results indicate that tibial accelerations were significantly greater in the footwear designed to improve energy return. In addition the 3-D kinematic analysis also showed that peak eversion and tibial internal rotation were significantly greater in the footwear designed to improve energy return. On the basis of these observations the current investigation suggests that these new footwear may place runners at an increased risk from chronic injury.
\end{abstract}

Keywords: accelerometry, ground reaction force, shock attenuation, energy absorbed, energy returned, running efficiency

\section{Introduction}

Distance running represents a popular physical activity that has been demonstrated as being physiologically beneficial to those who take part (Wen, 2007). Despite the clear health benefits and popularity of running, runners are known to be highly susceptible to chronic injuries with an incidence rate of around $70 \%$ during the course of a year (Marti et al., 1984). Thus, runners have sought numerous strategies in order to attenuate the risk of injury and improve their performance. One strategy is to utilise athletic footwear with appropriate mechanical characteristics; the properties of athletic footwear have been linked to the prevention of running injuries and improvement of performance (Shorten, 1993).
Running economy, which reflects the extent of inspired oxygen necessary to sustain a pre-set running velocity, has been shown to be a key determining factor in the determination of running performance (Lucia et al., 2006; Weston et al., 2000). The propensity for running footwear to influence running economy has been examined previously. It has been established that it is more efficient to utilise footwear with appropriate midsole mechanical characteristics (Bosco et al., 1983; Frederick et al., 1986). The concept of footwear energy return was developed to define the storage and reclamation of the strain energy produced when the shoe midsole deforms as a result of footstrike (Frederick et al., 1986). It has been hypothesised that increasing the energy returned from the shoe midsole can reduce the oxygen cost of running and thus facilitate an increase in performance. 
New commercially available footwear have been designed which utilise an expanded thermoplastic polyurethane midsole as opposed to more traditional ethylene vinyl acetate materials. This new midsole material claims to be more compliant and associated with reduced energy loss in comparison to traditional footwear midsoles (Worobets et al., 2013). Woborets et al. (2013) examined the influence of these new footwear on running economy using both treadmill and overground protocols. It was shown that the footwear designed to promote energy return were associated with significant increases in running economy in both treadmill (0.9\%) and overground situations (1.1\%). This supports the notion that they may be able to mediate positive alterations in performance. However, whilst the effectiveness of these new footwear has been established in terms of their ability to influence performance (Worobets et al., 2013), they have not been examined previously with regards to their ability to attenuate the impact parameters and coronal/transverse plane rotations linked to the aetiology of injury.

Therefore, the clinical efficacy of these new footwear in relation to lower extremity injuries is not yet known. As such, the aim of the current investigation is to examine the 3-D kinetics and kinematics of footwear designed to promote energy return in relation to conventional running trainers.

\section{Materials and methods}

\section{Participants}

Fifteen male participants volunteered to take part in the current investigation. All were free from musculoskeletal pathology at the time of data collection and provided written informed consent. The procedure utilised for this investigation was approved by the University of Central Lancashire ethical committee in accordance with the principles outlined in the Declaration of Helsinki. The mean \pm standard deviation characteristics of the participants were; age $21.02 \pm 2.02$ years, height $176.6 \pm 5.3 \mathrm{~cm}$ and body mass $76.82 \pm 6.27 \mathrm{~kg}$.

\section{Experimental footwear}

The training shoes (shoe size 8-10 UK men's) used during the current investigation consisted of conventional footwear (Saucony pro grid guide II; Saucony, Richmond, IN, USA) and commercially available footwear which claims to boost energy footwear (Adidas energy boost; Adidas, Herzogenaurach, Germany). Participants were given time to accommodate to each footwear condition. This involved 5 min of running in the experimental area.

\section{Procedure}

The runners completed five successful trials in which they ran through a $22 \mathrm{~m}$ walkway at an average velocity of $4.0 \mathrm{~m} / \mathrm{s}$ in each running shoe condition. The participants struck an embedded piezoelectric force platform (Kistler Instruments, Amherst, NY, USA) with their right foot (Sinclair et al., 2014). The force platform was collected with a frequency of $1000 \mathrm{~Hz}$. Running velocity was controlled using timing gates (SmartSpeed Ltd., Jarrow, UK) and a maximum deviation of $5 \%$ from the pre-determined velocity was allowed. 3-D kinematic information from the stance phase of the running cycle were obtained using an eight camera motion capture system (Qualisys Medical AB, Goteburg, Sweden) with a capture frequency of $250 \mathrm{~Hz}$. The order in which participants performed in each footwear condition was counterbalanced. The stance phase was delineated as the duration over which $>20 \mathrm{~N}$ of vertical force was applied to the force platform.

The calibrated anatomical systems technique was utilised to quantify lower extremity kinematics (Cappozzo et al., 1995). In order to define the anatomical axes of the right thigh, shank and foot segments $19 \mathrm{~mm}$ circular retroreflective markers were positioned unilaterally at the, calcaneus, $1^{\text {st }}$ and $5^{\text {th }}$ metatarsal heads, medial and lateral malleoli, medial and lateral epicondyle of the femur and contralaterally to the greater trochanter and iliac crest positions. The pelvis segment was defined using markers attached to the left and right anterior superior iliac spines (ASIS) and posterior superior iliac spines (PSIS). The hip joint centre was estimated equations based on the position of the ASIS markers (Sinclair et al., 2013b). To track the shank and thigh segments rigid carbon fibre clusters were utilised. The pelvis and foot segments were tracked using the ASIS and PSIS markers and the calcaneus, $1^{\text {st }}$ and $5^{\text {th }}$ metatarsal markers respectively. Static calibration trials were conducted with participants in the anatomical position allowing the anatomical markers to be referenced in relation to the tracking markers/clusters.

Tibial accelerations were measured using a uni-axial accelerometer (ACL 300; Biometrics, Newport, UK) which collected data at $1000 \mathrm{~Hz}$. The device was screw fixed into a piece of carbon-fibre material in accordance with the protocol documented by Sinclair et al. (2010). The accelerometer was mounted to the distal tibia in line with its axial axis $0.08 \mathrm{~m}$ above the centre of the medial malleolus. Strong non-stretch tape was used to mount the accelerometer to the tibia and reduce the risk of contaminating the acceleration signal as a function of tissue artefact (Greenhalgh et al., 2012). 


\section{Data processing}

Trials were processed in Qualisys Track Manager in order to identify anatomical and tracking markers then exported as C3D files. Kinematic parameters were quantified using Visual 3-D (C-Motion Inc, Gaithersburg, MD, USA) after marker data was smoothed using a low-pass Butterworth $4^{\text {th }}$ order zero-lag filter at a cut-off frequency of $15 \mathrm{~Hz}$. Kinematics of the hip, knee, ankle and tibial segment were quantified using an XYZ cardan sequence of rotations (where $\mathrm{X}$ is flexion-extension; $\mathrm{Y}$ is ab-adduction and is $\mathrm{Z}$ is internal-external rotation). All data were normalised to $100 \%$ of the stance phase then processed gait trials were averaged. The 3-D kinematic measures from the hip, knee, ankle and tibia which were extracted for statistical analysis were (1) angle at footstrike, (2) angle at toe-off, (3) peak angle during stance, and (4) peak ROM from footstrike to peak angle.

From the force platform vertical force parameters of impact peak, time to impact peak, average loading rate and instantaneous loading rate were calculated. The impact peak was taken as the vertical ground reaction force peak that occurred early in the stance phase. The average loading rate was calculated by dividing the impact peak by the duration over which the impact peak occurred. The instantaneous loading rate was calculated as the maximum increase between adjacent data points. The acceleration signal was filtered with a $60 \mathrm{~Hz}$ low-pass Butterworth $4^{\text {th }}$ order zero-lag filter. Peak tibial acceleration was defined as the highest positive acceleration peak measured during the stance phase. Tibial acceleration slope was quantified by dividing the peak tibial acceleration magnitude by the duration over which the acceleration occurred.

\section{Statistical analysis}

Means and standard deviations of 3-D kinematic and kinetic parameters were calculated for each footwear condition. Differences in kinetics and 3-D kinematics between footwear were examined using paired samples t-tests with significance accepted at the $P \leq 0.05$ level (Sinclair et al., 2013a). Effect sizes for all significant observations were calculated using Cohen's D. Shapiro Wilk tests were used to screen the data for normality, which confirmed that the normality assumption was not violated. All statistical analyses were conducted using SPSS 21.0 (SPSS Inc., Chicago, IL, USA).

\section{Results}

\section{Kinetics}

Table 1 presents the kinetic variables obtained as a function of both footwear conditions. The results show that peak tibial acceleration was significantly $\left(\mathrm{t}_{(14)}=3.26, P<0.05\right.$, $D=1.74$ ) greater in the footwear designed to boost energy return compared to the conventional shoe condition.

\section{3-D kinematics}

Figures 1 and 2 present the stance phase 3-D kinematic curves from the hip, knee, ankle and tibia. Tables 2-5 show the discrete 3-D kinematic parameters from the hip, knee, ankle and tibia, respectively, for both footwear types. The kinematic results show that ankle eversion was significantly $\left(\mathrm{t}_{(14)}=2.75, P<0.05, D=1.47\right)$ greater in the footwear designed to improve energy return compared to the conventional running shoes. It was also shown that tibial internal rotation was significantly $\left(\mathrm{t}_{(14)}=2.88, P<0.05, D=1.54\right)$ higher in the footwear designed to improve energy return.

Table 1. Kinetic and temporal parameters (mean \pm standard deviation(SD)) as a function of footwear.

\begin{tabular}{|c|c|c|c|c|}
\hline & \multicolumn{2}{|c|}{ Conventional } & \multicolumn{2}{|c|}{ Energy return } \\
\hline & Mean & SD & Mean & SD \\
\hline Impact peak (BW) & 1.90 & 0.22 & 1.88 & 0.29 \\
\hline Time to impact peak (s) & 0.03 & 0.01 & 0.03 & 0.01 \\
\hline Average loading rate (BW/s) & 60.40 & 13.88 & 63.17 & 16.94 \\
\hline Instantaneous loading rate (BW/s) & 111.06 & 38.69 & 119.51 & 30.61 \\
\hline Peak tibial acceleration (g) & 5.25 & 1.43 & $5.90^{\mathrm{a}}$ & 1.58 \\
\hline Time to peak tibial acceleration (s) & 0.03 & 0.00 & 0.04 & 0.03 \\
\hline Tibial acceleration slope (g/s) & 180.43 & 78.48 & 189.69 & 64.78 \\
\hline Stance time $(\mathrm{s})$ & 0.22 & 0.01 & 0.23 & 0.02 \\
\hline
\end{tabular}



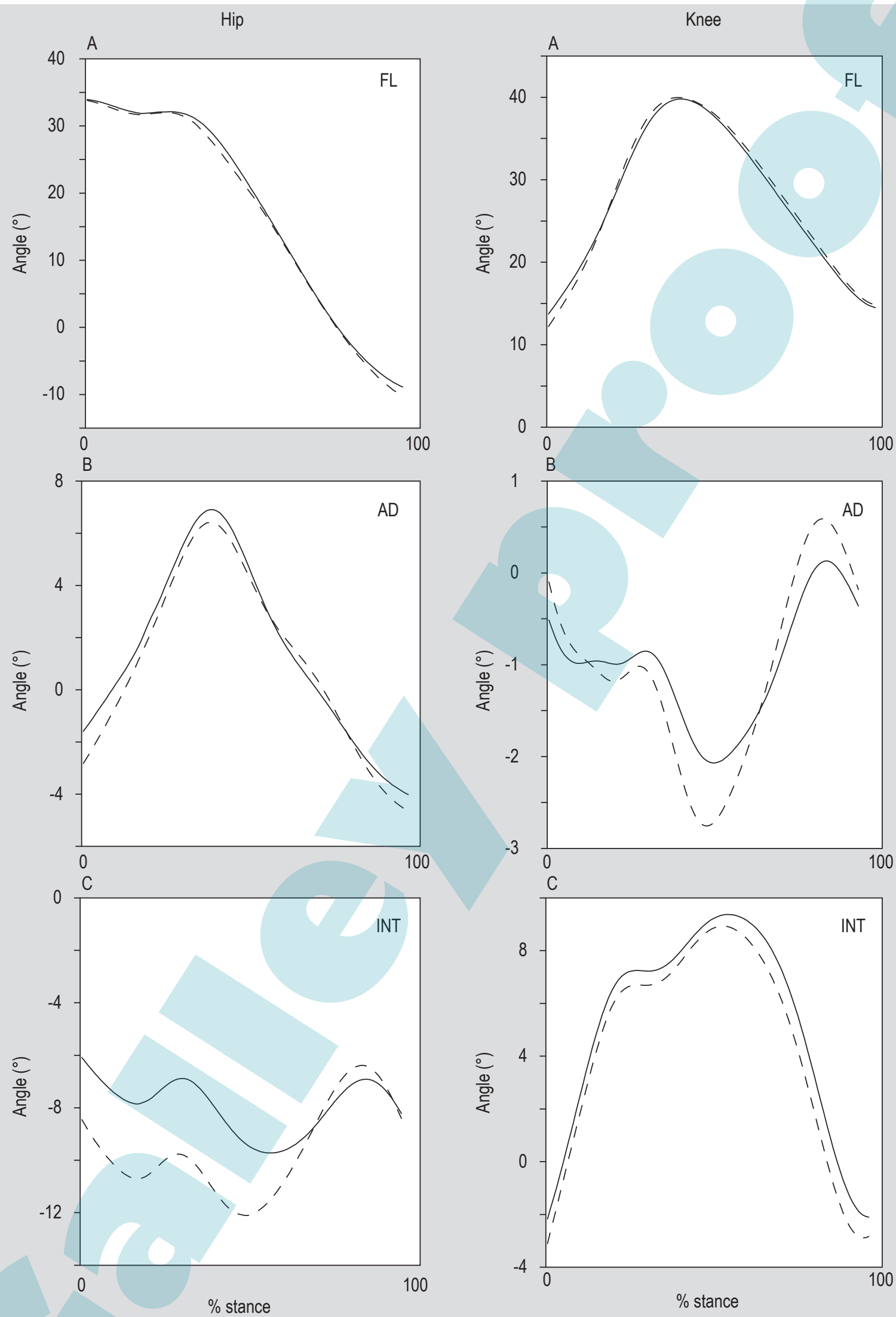

Figure 1. Hip and knee joint kinematics as a function of footwear (black = energy return, dot $=$ conventional) $(F L=$ flexion, $A D=$ adduction, INT = internal). 


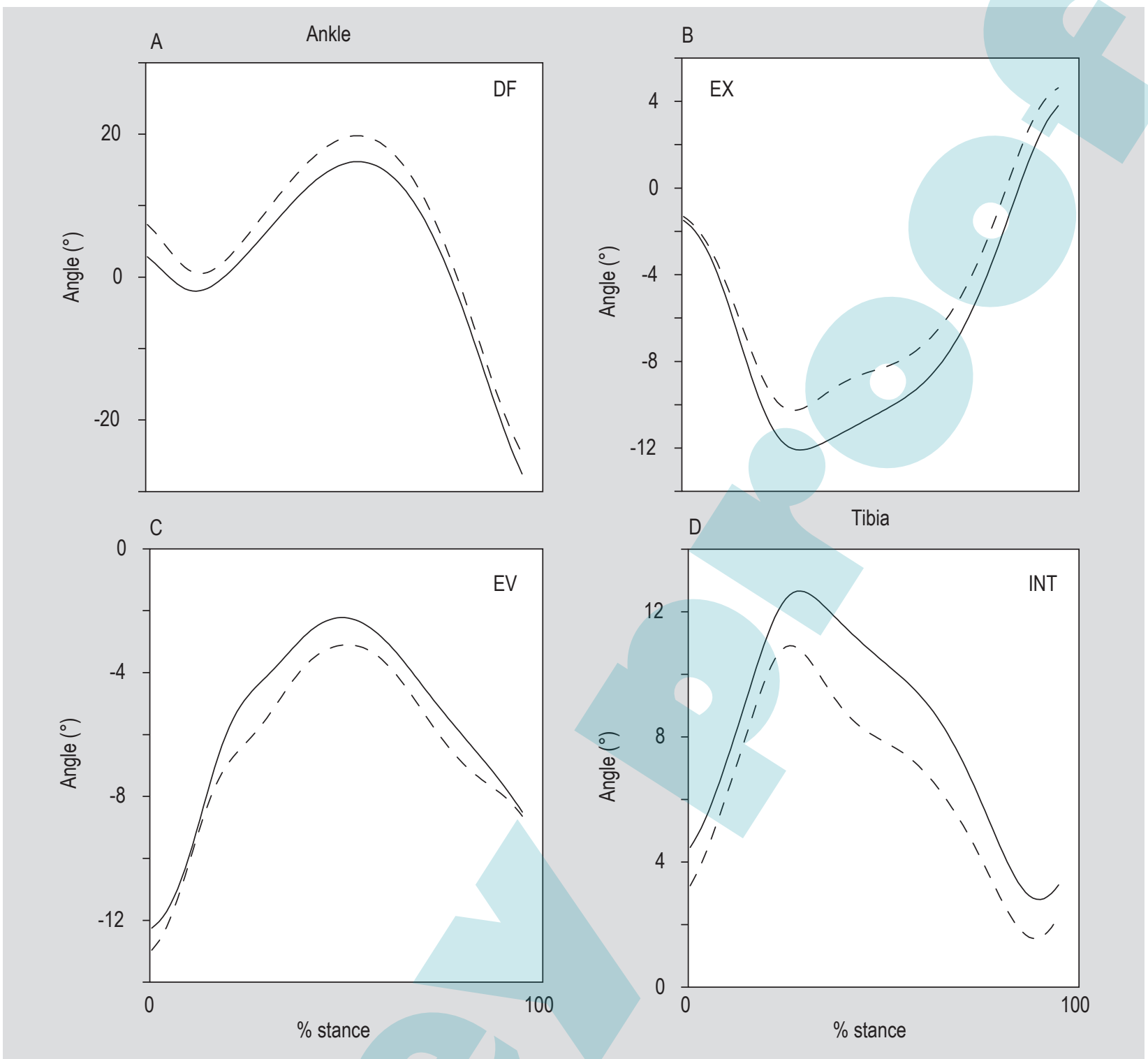

Figure 2. Ankle and tibial kinematics as a function of footwear (black $=$ energy return, dot $=$ conventional) (DF $=$ dorsiflexion, EV = eversion, $E X=$ external, INT $=$ internal).

\section{Discussion}

The aim of the current investigation was to examine the kinetics and kinematics of energy return footwear in relation to conventional running trainers. This study represents the first to examine the potential clinical efficacy of energy return footwear in relation to traditional running trainers.

The first key observation from the current investigation is that peak tibial accelerations were found to be significantly greater in the footwear claimed to promote energy return in comparison to the conventional running trainers. This may be attributable to the midsole utilised in these footwear thermoplastic polyurethane, which although claimed to promote energy return may not be effective in attenuating transient accelerations of the tibia in comparison to traditional midsole materials. Although the vertical force parameters were not found to differ significantly between footwear conditions this finding may still have clinical significance as transient tibial accelerations have been implicated in the aetiology of chronic injury (Whittle, 1999). It is important to acknowledge the proposed correlation between tibial acceleration magnitude and the incidence of chronic injuries as the development of injury can potentially be attenuated by mitigating the magnitude of tibial accelerations (Whittle, 1999). Therefore, the significant reductions in impact magnitude observed as a function of different footwear suggest that running using conventional footwear may assist in the reduction of overuse injury occurrence associated with excessive impact transients in relation to the energy return shoes. 
Table 2. Hip joint kinematics (mean \pm standard deviation(SD)) as a function of footwear.

\begin{tabular}{|c|c|c|c|c|}
\hline \multirow[t]{2}{*}{ Hip } & \multicolumn{2}{|c|}{ Energy return } & \multicolumn{2}{|c|}{ Conventional } \\
\hline & Mean & SD & Mean & SD \\
\hline \multicolumn{5}{|c|}{ Sagittal plane (+ = flexion / - = extension) } \\
\hline Angle at heelstrike $\left({ }^{\circ}\right)$ & 33.94 & 11.09 & 33.79 & 11.78 \\
\hline Angle at toe-off $\left({ }^{\circ}\right)$ & -7.79 & 9.76 & -10.27 & 11.34 \\
\hline Relative range of motion $\left({ }^{\circ}\right)$ & 1.02 & 1.88 & 0.81 & 1.2 \\
\hline Peak flexion $\left({ }^{\circ}\right)$ & 34.96 & 11.96 & 34.6 & 12.15 \\
\hline \multicolumn{5}{|c|}{ Coronal plane (+ = adduction / - = abduction) } \\
\hline Angle at heelstrike $\left({ }^{\circ}\right)$ & -1.59 & 6.96 & -2.73 & 6.66 \\
\hline Angle at toe-off $\left({ }^{\circ}\right)$ & -3.82 & 7.4 & -4.72 & 6.16 \\
\hline Relative range of motion $\left({ }^{\circ}\right)$ & 8.99 & 4.98 & 9.71 & 5.4 \\
\hline Peak adduction $\left({ }^{\circ}\right)$ & 7.4 & 7.2 & 6.98 & 5.65 \\
\hline \multicolumn{5}{|c|}{ Transverse plane (+ = internal $/$ - = external) } \\
\hline Angle at heelstrike $\left({ }^{\circ}\right)$ & -6.09 & 12.44 & -8.46 & 13.03 \\
\hline Angle at toe-off $\left({ }^{\circ}\right)$ & -8.09 & 9.36 & -8.49 & 11.07 \\
\hline Relative range of motion $\left({ }^{\circ}\right)$ & 7.31 & 5.84 & 6.46 & 5.2 \\
\hline Peak external rotation $\left({ }^{\circ}\right)$ & -13.4 & 10.28 & -14.93 & 11.96 \\
\hline
\end{tabular}

Table 3. Knee joint kinematics (mean \pm standard deviation (SD)) as a function of footwear.

\begin{tabular}{|c|c|c|c|c|}
\hline \multirow[t]{2}{*}{ Knee } & \multicolumn{2}{|c|}{ Energy return } & \multicolumn{2}{|c|}{ Conventional } \\
\hline & Mean & SD & Mean & SD \\
\hline \multicolumn{5}{|c|}{ Sagittal plane (+ = flexion $/$ - = extension) } \\
\hline Angle at heelstrike $\left(^{\circ}\right)$ & 13.70 & 5.94 & 12.18 & 5.19 \\
\hline Angle at toe-off $\left({ }^{\circ}\right)$ & 14.39 & 4.72 & 14.76 & 5.12 \\
\hline Relative range of motion $\left({ }^{\circ}\right)$ & 26.20 & 5.53 & 27.92 & 4.80 \\
\hline Peak dorsiflexion $\left({ }^{\circ}\right)$ & 39.91 & 4.42 & 40.10 & 5.02 \\
\hline \multicolumn{5}{|c|}{ Coronal plane (+ = adduction / - = abduction) } \\
\hline Angle at heelstrike $\left({ }^{\circ}\right)$ & -0.51 & 6.19 & -0.13 & 5.25 \\
\hline Angle at toe-off $\left(^{\circ}\right)$ & -0.36 & 4.72 & -0.21 & 4.48 \\
\hline Relative range of motion $\left({ }^{\circ}\right)$ & 3.82 & 2.66 & 4.79 & 2.90 \\
\hline Peak eversion $\left({ }^{\circ}\right)$ & -4.33 & 6.15 & -4.92 & 6.49 \\
\hline \multicolumn{5}{|c|}{ Transverse plane $(+=$ internal $/$ - = external) } \\
\hline Angle at heelstrike $\left(^{\circ}\right)$ & -2.18 & 9.25 & -2.80 & 11.75 \\
\hline Angle at toe-off $\left({ }^{\circ}\right)$ & -2.00 & 9.49 & -2.67 & 10.01 \\
\hline Relative range of motion $\left({ }^{\circ}\right)$ & 12.99 & 5.64 & 13.17 & 6.43 \\
\hline Peak external rotation $\left({ }^{\circ}\right)$ & 10.81 & 6.74 & 10.37 & 8.55 \\
\hline
\end{tabular}

A further key finding is that peak eversion and tibial internal rotation were shown to be significantly greater in the energy return footwear. This observation may have further clinical significance as increases in both ankle eversion and internal tibial rotation have been implicated in the aetiology of a number of overuse pathologies as a function of running activities, such as tibial stress syndrome, plantar fasciitis, patellofemoral syndrome and illiotibial band syndrome (Duffey et al., 2000; Lee et al., 2010; Willems et al., 2006). Furthermore, this also provides further evidence that conventional footwear may have the potential to attenuate the incidence of chronic injuries compared to the shoes that claim to increase energy return. It is hypothesised that this may again relate to the midsole materials utilised in these footwear; the deformation characteristics of the midsole may be such that they are unable to physically restrain the coronal plane motion of the ankle.

A possible limitation of the current investigation is that it focussed on the kinetics and kinematics of running. This 
Table 4. Ankle joint kinematics (mean \pm standard deviation(SD)) as a function of footwear.

\begin{tabular}{|c|c|c|c|c|}
\hline \multirow[t]{2}{*}{ Ankle } & \multicolumn{2}{|c|}{ Energy return } & \multicolumn{2}{|c|}{ Conventional } \\
\hline & Mean & SD & Mean & SD \\
\hline \multicolumn{5}{|c|}{ Sagittal plane (+ = dorsiflexion / - = plantarflexion) } \\
\hline Angle at heelstrike $\left({ }^{\circ}\right)$ & 2.82 & 8.52 & 7.23 & 9.20 \\
\hline Angle at toe-off $\left({ }^{\circ}\right)$ & -27.04 & 8.33 & -25.14 & 7.95 \\
\hline Relative range of motion $\left({ }^{\circ}\right)$ & 13.56 & 4.71 & 12.67 & 4.80 \\
\hline Peak dorsiflexion $\left({ }^{\circ}\right)$ & 16.35 & 5.42 & 19.89 & 7.93 \\
\hline \multicolumn{5}{|c|}{ Coronal plane $(+=$ inversion $/$ - = eversion $)$} \\
\hline Angle at heelstrike $\left({ }^{\circ}\right)$ & -1.29 & 4.73 & -2.43 & 3.85 \\
\hline Angle at toe-off $\left({ }^{\circ}\right)$ & 3.28 & 4.05 & 2.84 & 3.88 \\
\hline Relative range of motion $\left({ }^{\circ}\right)$ & 13.88 & 1.65 & 12.55 & 1.43 \\
\hline Peak eversion $\left({ }^{\circ}\right)$ & $12.87^{a}$ & 4.00 & 10.01 & 3.55 \\
\hline \multicolumn{5}{|c|}{ Transverse plane $(+=$ external $/$ - = internal) } \\
\hline Angle at heelstrike $\left({ }^{\circ}\right)$ & 4.46 & 3.82 & 3.25 & 3.94 \\
\hline Angle at toe-off $\left({ }^{\circ}\right)$ & 3.37 & 4.45 & 2.19 & 5.28 \\
\hline Relative range of motion $\left({ }^{\circ}\right)$ & 8.79 & 2.21 & 8.27 & 2.62 \\
\hline Peak external rotation $\left(^{\circ}\right)$ & 13.25 & 4.16 & 11.52 & 4.50 \\
\hline
\end{tabular}

Table 5. Tibial kinematics (mean \pm standard deviation (SD)) as a function of footwear.

\begin{tabular}{|c|c|c|c|c|}
\hline \multirow[t]{2}{*}{ Tibia } & \multicolumn{2}{|c|}{ Energy return } & \multicolumn{2}{|c|}{ Conventional } \\
\hline & Mean & SD & Mean & SD \\
\hline \multicolumn{5}{|c|}{ Transverse plane (+ = internal / - = external) } \\
\hline Angle at heelstrike $\left({ }^{\circ}\right)$ & 4.46 & 3.82 & 3.07 & 4.00 \\
\hline Angle at toe-off $\left(^{\circ}\right)$ & 3.34 & 4.52 & 2.25 & 5.24 \\
\hline Relative range of motion $\left({ }^{\circ}\right)$ & 9.25 & 4.16 & 10.33 & 4.68 \\
\hline Peak internal rotation $\left({ }^{\circ}\right)$ & $13.02^{\mathrm{a}}$ & 2.21 & 10.05 & 2.63 \\
\hline
\end{tabular}

is has been demonstrated as an effective technique to investigate how footwear affects the mechanics of running and also to examine the clinical efficacy of different running trainers. However, the mechanical characteristics of the footwear designed to promote energy return are designed to mediate a reduction in metabolic cost of performing at a set velocity is considered to be a key factor for the determination of running performance (Sinclair et al., 2013c). Therefore, future analyses should also seek to further investigate the mechanisms by which these footwear may influence the energy requirements of running. Whilst significant differences were observed in tiblal accelerations and eversion/tibial internal rotation, the fact that only male runners were assessed may limit the generalisability of the findings from this study to female runners. Females have been shown to exhibit distinct kinetics and kinematics when compared to male recreational runners (Ferber et al., 2003; Sinclair et al., 2012). This suggests that the efficacy of the footwear examined during this investigation for female runners is unknown and future studies are needed to assess the efficacy of such footwear for a female sample.

In conclusion, the current investigation provides new information describing the influence of commercially available footwear claimed to increase energy return on the kinetics and 3-D kinematics of running. On the basis that increased tibial accelerations and ankle eversion/ tibial internal rotation were observed when running in the footwear which aims to increase energy return, the current investigation suggests that these new footwear may place runners at an increased risk of chronic injury. This study indicates that for runners who are susceptible 
to chronic injuries related to excessive impact forces and rearfoot eversion a more conventional footwear may be more effective in reducing the risk of lower extremity injuries during running.

\section{References}

Bosco, C. and Rusko, H., 1983. The effect of prolonged skeletal muscle stretch-shortening cycle on recoil of elastic energy and on energy expenditure. Acta Physiologica Scandinavia 119: 219-224.

Cappozzo, A., Catani, F., Croce, U.D. and Leardini, A., 1995. Position and orientation in space of bones during movement: Anatomical frame definition and determination. Clinical Biomechanics 10: 171-178.

Duffey, M.J., Martin, D.F., Cannon, D.W., Craven, T. and Messier, S.P., 2000. Etiologic factors associated with anterior knee pain in distance runners. Medicine and Science in Sports and Exercise 32: 1825-1832.

Ferber, R., Davis, I.M. and Williams, D.S., 2003 Gender differences in lower extremity mechanics during running. Clinical Biomechanics 18: 350-357.

Frederick, E.C., Howley, E.T. and Powers, S.K., 1986. Lower oxygen demands of running in soft-soled shoes. Research Quarterly in Exercise and Sport 57: 174-177.

Greenhalgh, A., Sinclair, J., Leat, A. and Chockalingam, N., 2012. Influence of footwear choice, velocity and surfaces on tibial accelerations experienced by field hockey participants during running. Footwear Science 4: 213-219.

Lee, S.Y., Hertel, J. and Lee, S.C., 2010. Rearfoot eversion has indirect effects on plantar fascia tension by changing the amount of arch collapse. The Foot 20: 64-70.

Lucia, A., Esteve-Lanao, J., Oliván, J., Gómez-Gallego, F., San Juan, A.F., Santiago, C., Pérez, M., Chamorro-Viña, C. and Foster, C., 2006. Physiological characteristics of the best Eritrean runners exceptional running economy. Applied Physiology and Nutrition Metabolism 31: 530-540.

Marti, B., Vader, J.P., Minder, C.E. and Abelin, T., 1988. On the epidemiology of running injuries the 1984 bern grand-prix study. American Journal of Sports Medicine 16: 285-294.
Shorten, M.R., 1993. The energetics of running and running shoes. Journal of Biomechanics 26: S41-S51.

Sinclair, J., Bottoms, L., Taylor, K. and Greenhalgh, A., 2010. Tibial shock measured during the fencing lunge: the influence of footwear. Sports Biomechanics 9: 65-71.

Sinclair, J., Greenhalgh, A., Edmundson, C.J., Brooks, D. and Hobbs, S.J., 2012. Gender differences in the kinetics and kinematics of distance running: implications for footwear design, International Journal of Sports Science and Engineering 6: 118-128.

Sinclair, J., Hobbs, S.J., Taylor, P.J., Currigan, G. and Greenhalgh, A., 2014. The influence of different force and pressure measuring transducers on lower extremity kinematics measured during running. Journal of Applied Biomechanics 31: 166-72.

Sinclair, J., Taylor, P.J. and Hobbs, S.J., 2013a. Alpha level adjustments for multiple dependent variable analyses and their applicability - a review. International Journal of Sports Science and Engineering 7: 17-20.

Sinclair, J., Taylor, P.J., Currigan, G. and Hobbs, S.J., 2013b. The test-retest reliability of three different hip joint centre location techniques. Movement and Sports Sciences 83: 31-39.

Sinclair, J., Taylor, P.J., Edmundson, C.J., Brooks, D., and Hobbs, S.J., 2013c. The influence of footwear kinetic, kinematic and electromyographical parameters on the energy requirements of steady state running. Movement and Sports Sciences 80: 39-49.

Wen, D.Y., 2007. Risk factors for overuse injuries in runners. Current Sports Medicine Reports 6: 307-313.

Weston, A.R., Mbambo, Z. and Myburgh, K.H., 2000. Running economy of African and Caucasian distance runners. Medicine and Science in Sports and Exercise 32: 1130-1134.

Whittle, M.W., 1999. The generation and attenuation of transient forces beneath the foot; a review. Gait and Posture 10: 264-275.

Willems, T.M., Witvrouw, E., De Cock, A. and De Clercq, D., 2006. A prospective study to gait related risk factors for exercise-related lower leg pain. Gait and Posture 23: 91-98.

Worobets, J., Tomarasa, E., Wannopa, J.W. and Stefanyshyn, D., 2013. Running shoe cushioning properties can influence oxygen consumption. Footwear Science 5: S75-S76. 